\title{
Drought Monitoring Methodology Based on AVHRR Images and SPOT Vegetation Maps
}

\author{
Mohammad Amin Owrangi ${ }^{1}$, Jan Adamowski ${ }^{2 *}$, Mehrdad Rahnemaei ${ }^{3}$, Ali Mohammadzadeh ${ }^{4}$, \\ Reza Afshin Sharifan ${ }^{3}$ \\ ${ }^{1}$ Department of Building, Civil and Environmental Engineering, Concordia University, Montreal, Canada \\ ${ }^{2}$ Department of Bioresource Engineering, Faculty of Agricultural and Environmental Sciences, McGill University, \\ Montreal, Canada \\ ${ }^{3}$ Department of Water Resources Engineering, Islamic Azad University, Shiraz, Iran \\ ${ }^{4}$ Department of Remote Sensing, Faculty of Geodesy and Geomatics Engineering, Khajeh Nasir Toosi University of \\ Technology, Tehran, Iran \\ E-mail:m_owrang@encs.concordia.ca,jan.adamowski@mcgill.ca,rahnemaei@iaushiraz.ac.ir, \\ a_mohammadzadeh@kntu.ac.ir, ras@iaushiraz.net \\ Received March 1, 2011; revised April 3, 2011; accepted May 8, 2011
}

\begin{abstract}
Many regions of the world are experiencing an increase in the frequency and intensity of droughts. The province of Fars, Iran, has faced particularly severe drought and ground water problems over the course of the last decade. However, previous research on the subject reveals a lack of useful information regarding droughts in this province. This paper presents a fast, efficient and reliable method that can be used to produce drought maps in which Advanced Very High Resolution Radiometer (AVHRR) images are processed and then compared with SPOT vegetation maps. Ten-day maximum Normalized Difference Vegetation Index (NDVI) maps were produced and vegetation drought indices such as the Vegetation Condition Index (VCI) were calculated. Furthermore, a Temperature Condition Index (TCI) was extracted from the thermal bands of AVHRR images in order to produce the Vegetation Health Index (VHI). Remotely sensed data was then compared with hydrological and meteorological data from 1998 to 2007. The Standardized Precipitation Index (SPI) was used to quantify the precipitation deficit while the Standard Water Level Index (SWI) was developed to assess the groundwater recharge deficit. Instead of correlation coefficients, spatial correlation through visual comparison was found to provide better and more meaningful pictures. The highest correlation values were obtained when VHI or Drought Severity Index (DSI) values were correlated with the current month's SWI data. DSI maps showed strong vegetation conditions existing for the majority of the study period. For most counties in Fars, strong Pearson correlations observed between the DSI and the SWI of the same month reflect high rates of ground water consumption. The results of this study indicate that the proposed method is a potentially promising method for early drought awareness which can be used for drought risk management in semi-arid climates such as in Fars, Iran. This study also recommends that the Iranian government develop programs to help decrease the consumption of ground water resources in the province of Fars to ensure the long term sustainability of the watersheds in this province.
\end{abstract}

Keywords: Drought, Remote Sensing, Water Resources, VHI, DSI, SWI

\section{Introduction}

In the past few decades, both the frequency and intensity of droughts have increased in a number of regions in the world [1,2]. This recurring trend has negatively impacted many of these areas in terms of the large annual losses in vegetation it causes. Because of the serious social, economic, and environmental ramifications, drought monitoring has become a high priority for many countries, and especially developing ones. Since the late 1980s, satellites have been used for detecting and monitoring droughts as well as assessing their impact on agriculture [3]. 
One of the most efficient monitoring methods involves the use of Remote Sensing Technology. With this technique, sensors operating in several spectral bands are mounted on satellites in order to rapidly obtain and distribute drought information over large geographic areas. While the satellite is in orbit, it is able to explore the earth's surface where in just a matter of a few days it is able to identify, monitor, and assess drought conditions. Using this technology, one can not only investigate the effect of droughts on vegetation cover but also their effects on ground water, surface temperature, and precipitation. In this way, a better understanding of temporal and spatial characteristics of the drought for a specific region can be achieved.

By monitoring droughts over a long period of time (i.e., 10 years or more) early drought warning systems can be developed. These early warning systems are important because they are being relied upon more and more to ensure global food security [4]. Previous methods of drought monitoring have typically used vegetation indices for drought monitoring. Kogan (1997) developed a method that analyzed the relationship between the Vegetation Condition Index and the Temperature Condition Index (VCI-TCI) [3]. Eklundh in 1996 assessed the possibility of using NDVI data for crop and natural vegetation monitoring by measuring the cross-correlation between the time series of NDVI and meteorological indicators such as rainfall (for areas where rainfall is a limiting factor) [5]. Eklundh's results showed that the correlation between NDVI and rainfall coefficients is quite high, between 0.7 and 0.9 , and that NDVI lags behind rainfall by one to three months. Eklundh concluded that if rainfall is to be used as an indicator of seasonal vegetation development, then there will also be certain limitations in the ability of NDVI's to monitor temporal vegetation variations.

Singh et al. (2003) used NDVI, VCI and TCI to monitor droughts as well as estimate vegetation health. In their research, they used both vegetation and temperature condition indices to monitor droughts in India [6]. Bhuiyan et al. (2006) developed a new SWI index to assess groundwater recharge-deficit [7]. The correlations of drought with respect to different indices are visually interpreted and necessitate certain disclaimers, namely that negative SPI anomalies do not always correspond to drought, and that a delay exists between hydrological and vegetative stress. There is also a delay between vegetative and hydrological stress. In order to identify a trend over 10 years, the annual rainfall was plotted against the cumulative annual NDVI values and it was found that the NDVI values were parallel to the rainfall, but with a time lag of one year. Thus, this 2006 study developed a hypothesis that there is a time lag between the rainfall and NDVI responses, and our study also rests on such a hypothesis. The results obtained with this method were compared with two other methods: 1) the relationship between NDVI and rainfall during the plant growing season, and 2) the relationship between NDVI and rainfall as well as NDVI and surface temperatures. The former characterizes the dynamics of vegetation development via its growing season's parameters on a consistent spatial scale, while the latter is based on the relationship between the Global Vegetation Index (GVI) and the Temperature Condition Index (TCI) with rainfall [8]. Bajgiran et al. (2008), using AVHRR images they obtained for 1997-2001, compared precipitation data in the north-west region of Iran with VCI and NDVI indices [9]. According to their results, both NDVI and VCI indices can be used to monitor regional droughts. A good linear correlation between monthly precipitation levels and NDVI or VCI amounts was observed and can possibly be used to predict and manage drought risk.

The aim of this research was to develop drought maps specifically for the southwest region of Iran, with a particular focus on the province of Fars, an area that has been suffering from disastrous hydrological drought since 2001. Despite the existence of previous research on the development of drought maps, a special method for extracting exact drought estimates for this particular Iranian region has yet to be developed. Previous research has typically relied on only one or two meteorological or hydrological indices. In our study, however, we incorporated remote-sensing data, related data from the NOAA-AVHRR sensor, and SPOT vegetation data (to verify extracted vegetation indices) to draw our conclusions.

In this study, analyses of monthly drought dynamics were calculated to identify drought configurations within hydrological, meteorological and vegetative domains. Making both quantitative and visual comparisons of drought dynamics in meteorological, hydrological, and vegetative domains in the province of Fars allowed us to generate more useful and reliable results. To verify the vegetation indices extracted from the NOAA-AVHRR images, SPOT-VEG images from the same time period (1998-2007) were used. The Standardized Water Level Index (SWI) and the Standard Precipitation Index (SPI) were used to monitor and analyze hydrological and meteorological drought, respectively. Normalized Difference Vegetation Index (NDVI), Vegetation Condition Index (VCI), Temperature Condition Index (TCI) and Vegetation Health Index (VHI) were used to assess vegetative drought. The development of VHI was done using VCI and TCI indices because they are more effective at monitoring vegetative drought than are other indices [6,10,11]. Given that the province of Fars is the most important agricultural region of Iran, the effects of its ground water consumption on NDVI were also investigated. The hydrological and meteorological stations of Fars are well distributed (geo- 
graphically) throughout the province, and temporal analysis was carried out over a span of 10 years. This specific time frame was used so that the long-term effects of precipitation and changing ground water levels could be studied. Compared with traditional in-situ measurements, the results obtained from remote-sensing methods are capable of providing more reliable drought maps. Chapter 3 explains our implementation methodology while Chapter 4 provides a comprehensive presentation and analysis of our results. Finally, concluding remarks are given in Chapter 5.

\section{Materials and Methods}

\subsection{Study Area}

Located in the southern part of the country, Fars is one of the 30 provinces that comprise present day Iran (Figure 1). As of 2006, the province was home to 4.34 million people, $62 \%$ of which are registered urban dwellers, $38.1 \%$ villagers, and $0.7 \%$ nomadic tribes. Three distinct climatic regions exist with the province's 122, $400 \mathrm{~km}^{2}$ territory: a mountainous area in the north and northwest characterized by moderately cold winters and mild summers; a central region with relatively rainy, mild winters and hot, dry summers; and a southern region with relatively rainy, mild winters and hot, dry summers. Shiraz is the capital and center of Fars. The province consists of the following counties: Estahban, Abadeh, Eqleed, Bovanat, Jahrum, Darab, Sepidan, Shiraz, Fasa, Firouzabad, Kazeroon, Lar, Lamerd, Marvdasht, Mamasani, Khonj and Nayriz. Agriculture is the most important activity in Fars, and its major products include cereal (wheat and barley), citrus fruits, dates, sugar, beets and cotton. From an agricultural point of view, Fars is one of the most strategic provinces in Iran, as it is responsible for producing $37 \%$ of the country's wheat.

\subsection{Satellite Data}

\subsubsection{Advanced Very High Resolution Radiometer (AVHRR) Images}

The image data taken by the Local Area Coverage Advanced Very High Resolution Radiometer (LAC AVHRR) aboard the National Oceanic and Atmospheric Administration (NOAA) 14-16-17 satellite were preprocessed using ENVI. For temporal analysis, a 10-year period was chosen in order to study the long-term effects of precipitation and groundwater levels on the vegetation coverage. This research was limited to ten years due to the inability to access any data records prior to 1998.

Initial examination of AVHRR data collected from the NOAA satellite database [12] revealed that a number of the images had severe cloud contamination and/or missing passes. Of the 254 images collected during 1998 - 2007 (April - September), 190 raw AVHRR images were selected.

\subsubsection{SPOT Vegetation Maps}

In order to study the vegetation cover in Fars, 10-day composite NDVI data (derived from the sensor VEGETATION on board the SPOT satellite platforms) was acquired from the "Vlaamse Instelling Voor Technologish Onderzoek” [13]. The SPOT-VGT S10 (10-day composite) NDVI composites have a spatial resolution of
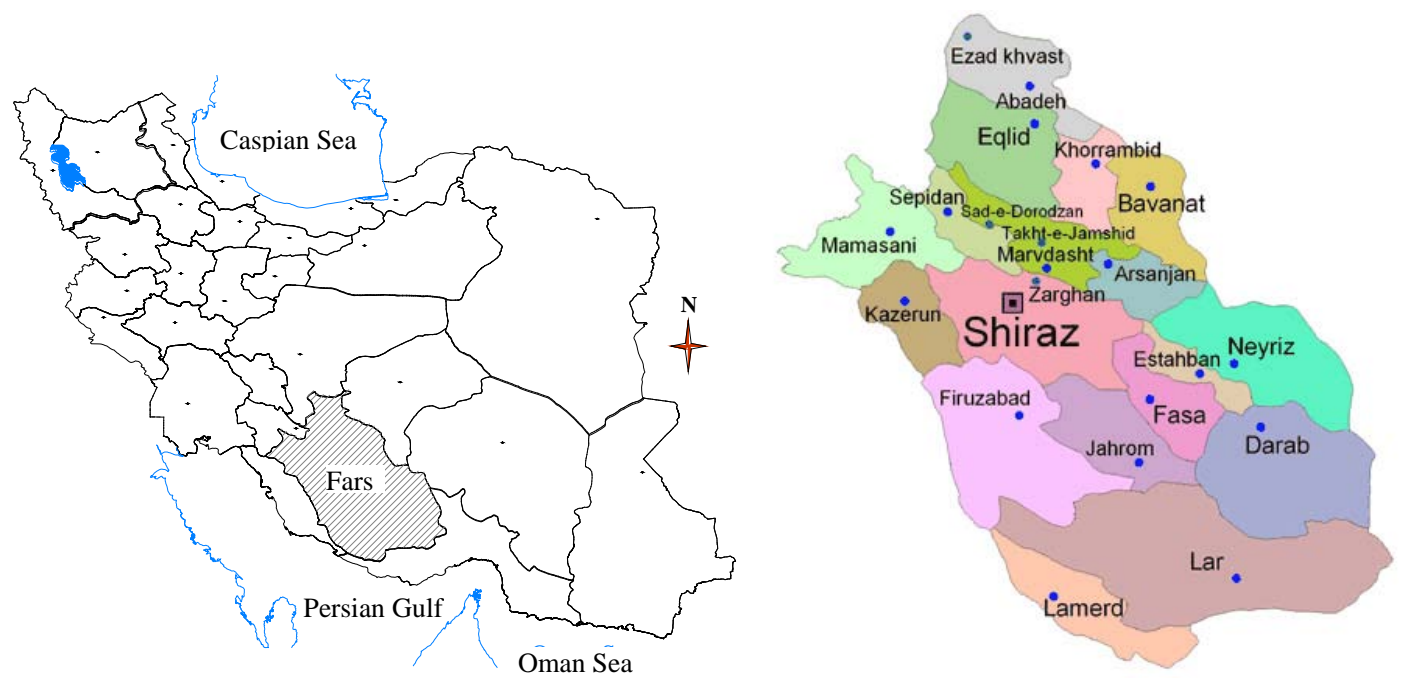

Figure 1. Study area: Map of Iran (left) and the various counties within the province of Fars (right). 
$1 \mathrm{~km}^{2}$ and were derived from primary SPOT-VGT products; the composites were corrected for reflectance, scattering, water vapor, ozone, and other gas absorption using the procedures described by Achard et al. and Duchemin et al. [14,15].

The maximum value compositing (MVC) procedure as described by Holben (1986) was used to merge NDVI values over the course of ten days [16]. The resulting surface reflectance value for each pixel thus corresponds to the date with the maximum NDVI-value in a 10-day period. Maximum value compositing for the synthesis of daily NDVI-values was found to be a reliable procedure for detecting changes in vegetation cover $[17,18]$.

Typical NDVI-values range between 0.1 and 0.7 for vegetated areas, with a higher (composite) NDVI value equating to denser, greener vegetation. The temporal evolution of NDVI-values is considered to be an effective way to analyze the impact of 1) natural seasonal variations, 2) extreme climatic events, and 3) human activities on ecosystems [19]. The temporal evolution of NDVI values for the period 1998 - 2005 were analyzed in four selected counties in Fars. For each county average, decadal NDVI-values on farmland were calculated by spatial aggregation of the $1 \mathrm{~km}^{2}$ pixels.

\subsection{Meteorological and Hydrological Data}

Figure 2 shows the precipitation data collected from 122 synoptic and rainfall stations in the study area over a ten-year period from 1998 to 2007. Groundwater-level data from 378 observer wells within Fars was also collected.

\section{Methodology}

Figure 3 shows the flowchart of the proposed drought

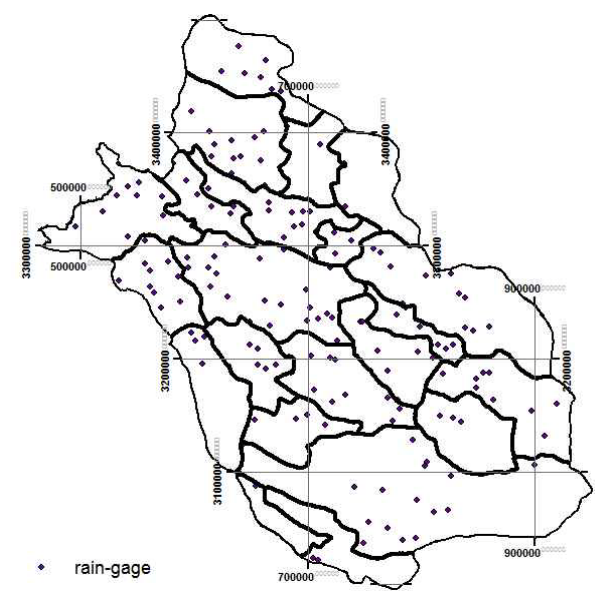

(a) monitoring methodology. In the first step, preprocessing including image georeferencing, radiometric gain and offset calibration of NOAA AVHRR images, and normalization of ground water level data are performed. The 10-day NOAA AVHRR data is used to produce NDVI images, which are then compared and validated using SPOT-VEG data. From this data, long-term mean NDVI and max/min NDVI values are produced, which are in turn used to calculate DSI and VCI. In order to calculate the SWI and SPI indices, groundwater and precipitation data are used (please see "Reference Data" in the flowchart below).

The next step in our proposed methodology is to use the DSI and VHI drought monitoring indices to derive drought severity maps. These drought maps are produced according to GIS standards and the results are discussed in the subsequent sections below. As shown in Figure 3, the DSI and VHI indices are also used to derive cor- relation coefficients. The correlation coefficients are calculated between SWI and VHI or between SWI and DSI. Visual spatial interpretations are performed to evaluate the spatial correlations that exist between SPI and VHI as well as between SPI and DSI (VHI is calculated from VCI and TCI indices).

\subsection{Preprocessing}

The five bands of raw AVHRR images were extracted using ENVI software, and radiometric calibrations were performed on bands 1 and 2 using calibration coefficients provided by NOAA. Digital number values were converted into an Albedo function using the following Equation (1):

$$
\text { Albedo }=A^{*} \mathrm{DN}+B
$$

where DN is the digital number of pixels and $A$ and $B$ are calibration coefficients provided by NOAA for NOAA-

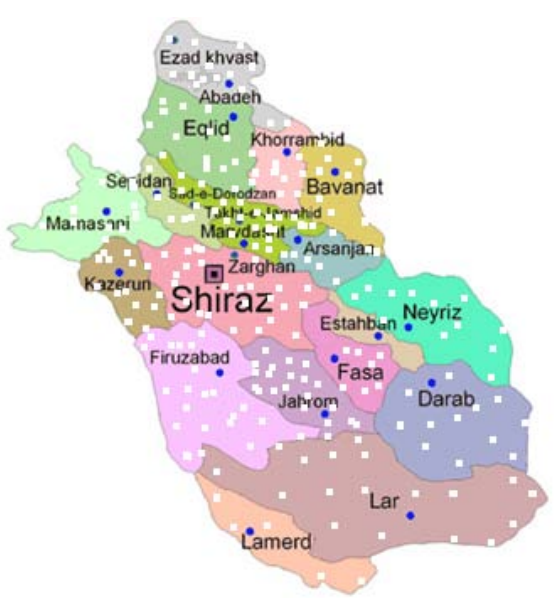

(b)

Figure 2. (a) Rain-gauge stations, (b) Observation wells in and around the province of Fars (Iran). 


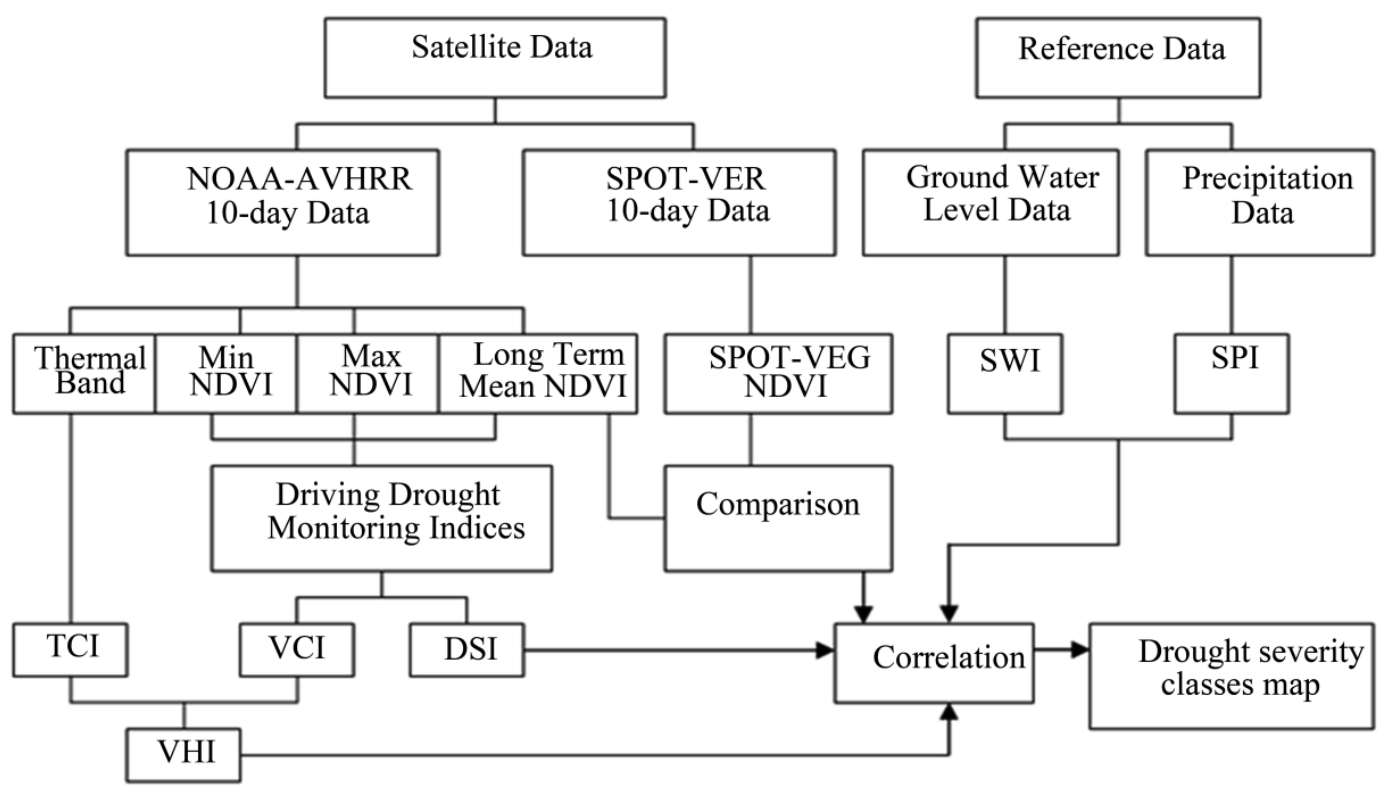

Figure 3. Flowchart of proposed method.

-14 [20].

Using ENVI software, geometric corrections for bands 1 and 2 of all the images were performed in two subsequent stages using ephemeris data and ground control points. In the ground control point method, polynomial transformation was employed and Root Mean Square error (RMS) values averaged around 0.65 pixels. The resulting images had a nominal spatial resolution of $1.1 \mathrm{~km}^{2}$. Also, ground water level data were normalized with respect to long-term annual mean values in order to produce SWI data.

Many researchers have been able to determine vegetation condition using vegetation indices such as NDVI [9, 21-25]. The NDVI is based on the fact that healthy vegetation has a low reflectance in the visible portion of the electromagnetic spectrum due to chlorophyll absorption and other pigments, and high reflectance in the Near Infrared (NIR) because of the internal reflectance by the mesophyll spongy tissue of a green leaf [26]. NDVI can be calculated using pixel's reflectance values of red (visible) band and the NIR band of a satellite sensor, and is represented by the following Equation (2):

$$
\mathrm{NDVI}=(\mathrm{NIR}-\mathrm{Red}) /(\mathrm{NIR}+\mathrm{Red})
$$

NDVI values range from -1 to +1 . Because of the high reflectance in the NIR portion of the electromagnetic spectrum, healthy vegetation is represented by high NDVI values between 0.05 and 1. Conversely, non-vegetated surfaces (such as water bodies) yield a negative NDVI value. Bare soil areas have NDVI values which are closest to 0 due to the high reflectance in both the visible and NIR portions of the electromagnetic spectrum [27].

Throughout each year of the study, images were collected from the same 10-day period for every month and the ones that had the least cloud contamination were selected to produce NDVI images. From these images, 10-day maximum NDVI monthly composites were subsequently generated. In order to validate these NDVI images, they were later compared to similar SPOT-VEG maps. After validating the NDVI images, min/max NDIV and long term NDVI images were obtained based on Maximum Value Composite (MVC) using ENVI software.

\subsection{Ground Drought Indices}

\subsubsection{Standardized Precipitation Index (SPI)}

Precipitation is the main factor which controls the formation and persistence of drought. Understanding that a deficit of precipitation has different impacts on ground water, reservoir storage, soil moisture, snow pack and stream flow led McKee et al. to develop the Standardized Precipitation Index (SPI) [28]. The SPI is a probability index that is based solely on precipitation and was designed to quantify the precipitation deficiency for multiple time scales. These time scales reflect the impact of drought on the availability of different water resources. A long-term precipitation record at the desired station is fitted to a probability distribution, which is then transformed into a standardized normal distribution so that the mean SPI is zero. Positive SPI values indicate precipitation that is greater than the mean, while negative values indicate pre- 
cipitation that is less than the mean. The SPI calculation for any location is based on the long-term precipitation record for a desired period and is calculated using the following Equation (3):

$$
\mathrm{SPI}=\left(\mathrm{P}_{\mathrm{i}}-\mathrm{P}_{\mathrm{m}}\right) / \sigma
$$

where $\mathrm{P}_{\mathrm{i}}$ is the seasonal precipitation, $\mathrm{P}_{\mathrm{m}}$ is the long-term mean, and $\sigma$ is the standard deviation of the long-term record. The drought categories defined by SPI values are listed below (Table 1).

\subsubsection{Standardized Water-Level Index (SWI)}

The Standardized Water-Level Index (SWI) was proposed in order to monitor anomalies in ground water levels [29]. Groundwater level data was obtained from the Ground Water Department in Shiraz, Fars. The SWI is computed by normalizing seasonal groundwater levels and dividing the difference between the seasonal water level and its long-term seasonal mean by the standard deviation. For normalization, an incomplete gamma function was used for water level data before using them for calculating SWI. SWI is an indicator of water-table decline and an indirect measure of recharge, and thus an indirect reference to drought (4):

$$
\mathrm{SWI}=\left(\mathrm{W}_{\mathrm{ij}}-\mathrm{W}_{\mathrm{im}}\right) / \sigma
$$

where $W_{i}$ is the seasonal water level for the $i^{\text {th }}$ well and $j^{\text {th }}$ observation, $\mathrm{W}_{\mathrm{im}}$ is the seasonal mean and $\sigma$ is the standard deviation. Since groundwater levels are measured from the ground surface to the bottom of the observation wells, positive anomalies correspond to water stress while negative anomalies represent a 'no drought' condition.

\subsection{Remote Sensed Indices}

\subsubsection{Drought Severity Index (DSI)}

NDVI by itself does not reflect drought or non-drought conditions. The severity of a drought or the extent of wetness can be expressed by a drought severity index.
This index is defined as a measure of the deviation of the current NDVI values from their long-term mean (5). Throughout the years of this research (i.e., 1998 to 2007), NDVI values were computed on a decadal basis for the months of April to September. Decadal, "long-term mean" NDVI maps covering the course of 10 years were created using the results from NOAA-AVHRR.

$$
\mathrm{DSI}=\mathrm{NDVI}_{\mathrm{i}}-\mathrm{NDVI}_{\mathrm{i}-\text { mean }}
$$

In the equation above, $\mathrm{NDVI}_{\mathrm{i}}$ represents the NDVI for month $\mathrm{i}$ and $\mathrm{NDVI}_{\mathrm{i} \text {-mean }}$ is the long-term NDVI mean for the month i. A negative DSI indicates below normal vegetation conditions and therefore suggests the presence of prevailing drought.

\subsubsection{Vegetation Condition Index (VCI)}

Although the NDVI has been used extensively in the past for vegetation monitoring, it is often very difficult to interpret in relation to vegetation conditions, especially when comparing different climate regions. In order to overcome this difficulty, Kogan (1995) created the Vegetation Condition Index (VCI) which compares the NDVI of the present month with the maximum and minimum NDVI (which is calculated using long-term records of RS images) [10]. VCI separates the short-term signal from the ecological signal, as demonstrated in (6):

$$
\mathrm{VCI}=\left(\mathrm{NDVI}_{\mathrm{j}}-\mathrm{NDVI}_{\min }\right) * 100 /\left(\mathrm{NDVI}_{\max }-\mathrm{NDVI}_{\text {min }}\right)
$$

where $\mathrm{NDVI}_{\max }$ and $\mathrm{NDVI}_{\text {min }}$ are calculated using the above equation. The condition of the ground vegetation presented by the VCI is measured as a percent. A 50\% VCI value reflects fair vegetation conditions, whereas values between $50 \%$ - $100 \%$ indicate optimal or abovenormal vegetation conditions. A VCI value of $100 \%$ means that the NDVI value for the selected month (week) is equal to the $\mathrm{NDVI}_{\max }$, which in turn means that optimal conditions for vegetation exist. Different degrees of drought severity are represented by any VCI value below 50\%. Kogan (1995) identified extreme drought conditions

Table 1. SPI, SWI and VHI classifications schemes.

\begin{tabular}{cccc}
$\begin{array}{c}\text { noitacifissalC } \\
\text { semehcS }\end{array}$ & $\begin{array}{c}\text { TPS } \\
\text { Drought Classes }\end{array}$ & $\begin{array}{c}\text { SWI } \\
\text { (Bhuiyan, 2004) }\end{array}$ & VHI (Kogan, 2001) \\
\hline Extreme drought & $<-2.0$ & $>2.0$ & $<10$ \\
Severe drought & $<-1.5$ & $>1.5$ & $<20$ \\
Moderate drought & $<-1.0$ & $>1.0$ & $<30$ \\
Mild drought & $<0.0$ & $>0.0$ & $<40$ \\
No drought & $>0.0$ & $<0.0$ & $>40$ \\
\hline
\end{tabular}


to be those that fell below a VCI threshold of 35\% [10]. He also suggested that further research be conducted in order to categorize drought severity for VCI values ranging from $0-35 \%$.

A VCI value close to $0 \%$ reflects an extremely dry month and an NDVI value that is close to its long-term minimum. Low VCI values that persist over several consecutive time intervals indicate the development of drought.

\subsubsection{Temperature Condition Index (TCI)}

During the rainy season in general, it is common for overcast conditions to prevail for up to three weeks. When conditions last longer than this, the weekly NDVI values tend to be depressed, giving the false impression of water stress or drought conditions. To remove the effects of contamination in satellite assessment of vegetation conditions, Kogan (1995, 1997) suggested the use of a Temperature Condition Index (TCI) $[3,10]$. The TCI is calculated much in the same way as the VCI, but its formulation is modified to reflect the vegetation's response to temperature (i.e. the higher the temperature the more extreme the drought). TCI is based on brightness temperature (BT) and represents the deviation of the current month's temperature from the recorded maximum. Using meteorological observations, as well as the relationship between ground surface temperature and moisture regimes, drought-affected areas can often be detected before biomass degradation occurs. Hence, TCI plays a key role in drought monitoring and is represented by (7):

$$
\mathrm{TCI}=\left(\mathrm{BT}_{\max }-\mathrm{BT}_{\mathrm{j}}\right) * 100 /\left(\mathrm{BT}_{\max }-\mathrm{BT}_{\min }\right)
$$

\subsubsection{Vegetation Health Index (VHI)}

While VCI and TCI are characterized by varying mois- ture and thermal conditions of vegetation, Vegetation Health Index (VHI) represents overall vegetation health. Kogan (2001) assigned five different drought classes to VHI in order to more properly construct drought maps, as shown in Table 1 below [11]. VHI is computed using the following Equation (8):

$$
\mathrm{VHI}=0.5(\mathrm{VCI})+0.5(\mathrm{TCI})
$$

\section{Results and Discussion}

As previously mentioned, preprocessing was applied to the input data in order to obtain the 10-day NDVI images as well as the long-term and min/max NDVI values. Figure 4 shows the validation results by comparing NDVI values of NOAA-AVHRR with SPOT-Vegetation maps. Pearson correlation shows $\mathrm{R}$ around 0.87 . Therefore, SOPT-Vegetation is a good substance for missing AVHRR data.

Which is SPI and SWI were subsequently calculated from long-term precipitation and ground water data. VHI maps (See Figure 5(b)) were calculated using TCI and VCI values. Drought severity index (DSI) maps (See Figure 6) were then produced using long-term NDVI means. Different time lags were examined in order to investigate the correlation between SPI, DSI, and VHI. The same was done in order to interpret the SWI in relation to DSI and VHI responses. If and when the scales of the parameters are the same, spatial correlation coefficients (Pearson or Superman) generally yield "good” results (i.e., meaningful interpretations can be made).

However, when the parameters are different, there is a higher chance of witnessing weak correlations, even though the parameters are entirely dependent on one

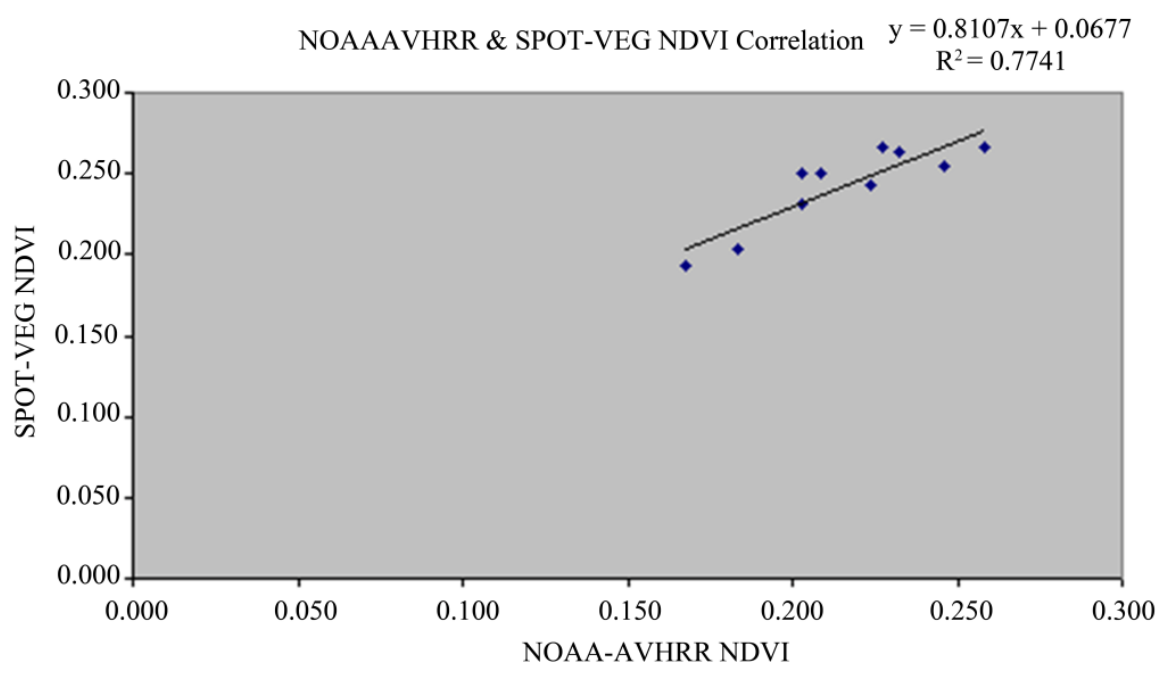

Figure 4. Validation between AVHRR NDVI and SPOT-VEG. 


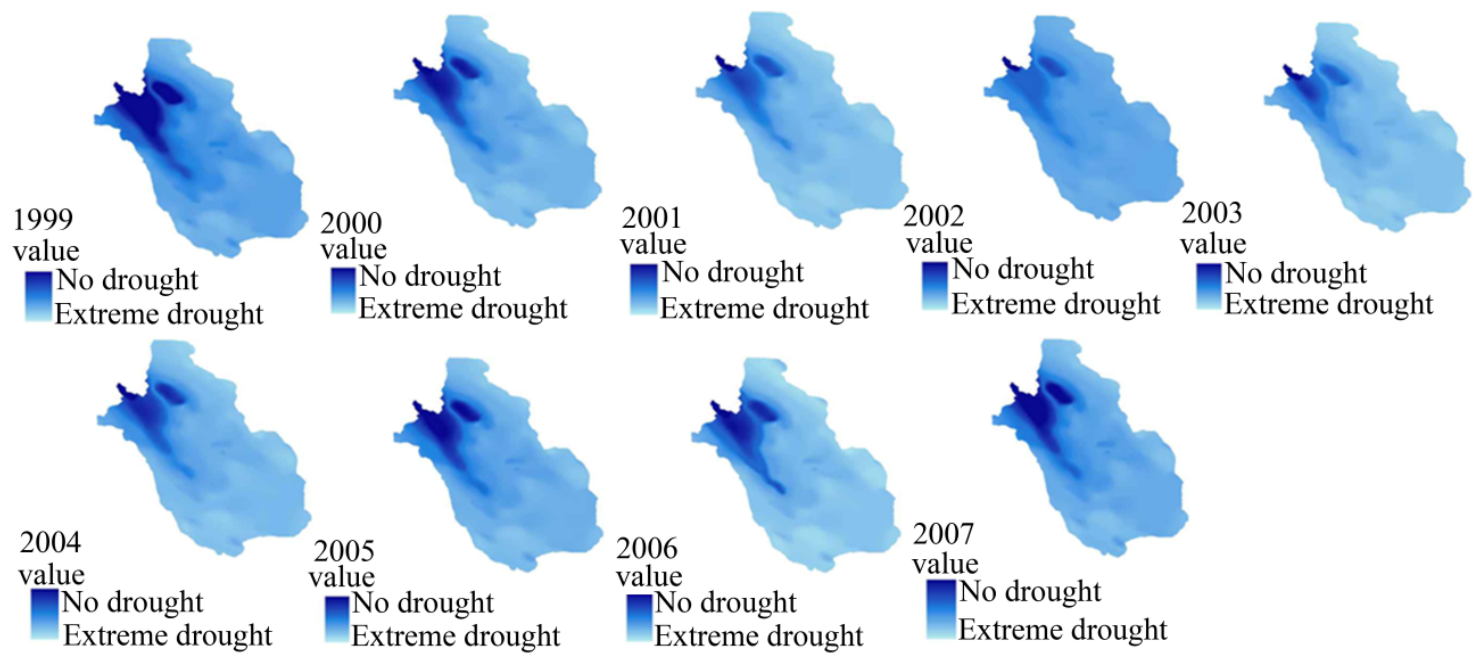

(a)

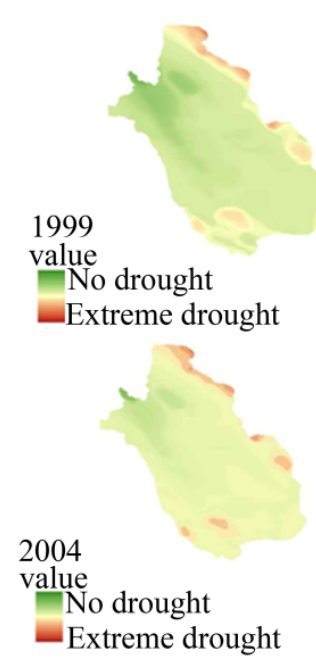

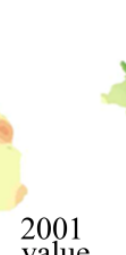
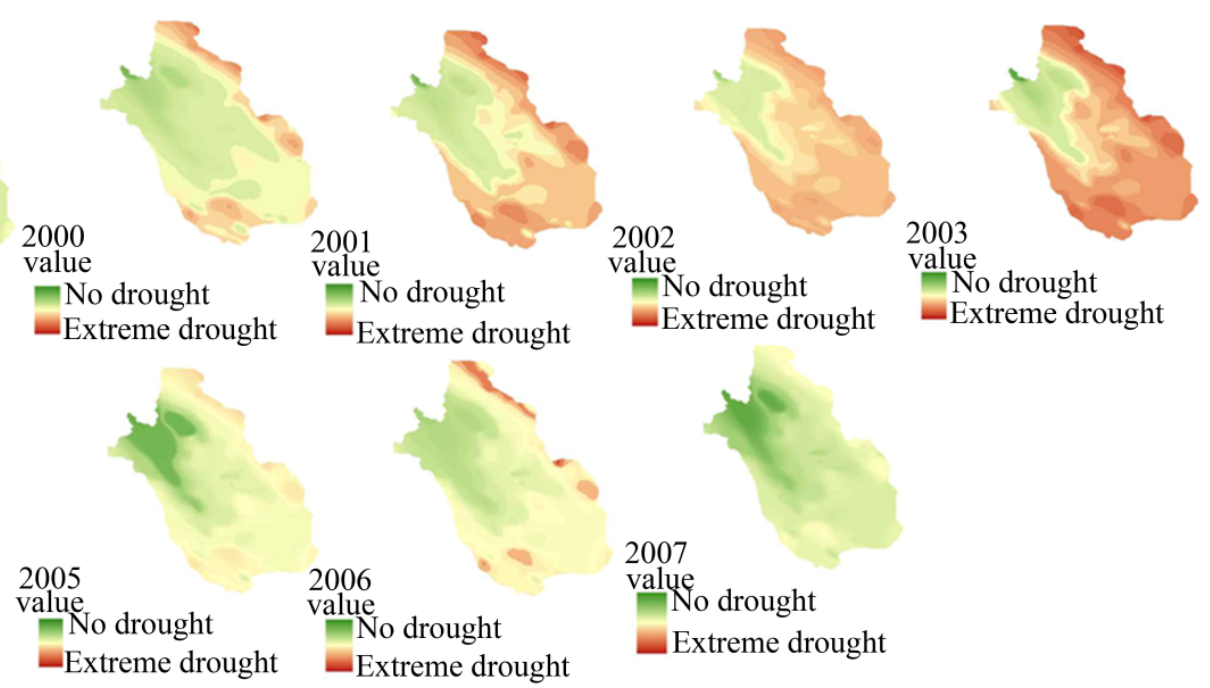

No drought
Extreme drought

No drought

Extreme drought

(b)

Figure 5. Visual spatial correlation between (a) SPI and (b) VHI during 1999 - 2007.

another. This chance is higher when values are interpolated since interpolation techniques involve different mathematical functions which again generate errors. Therefore, instead of relying upon correlation coefficients, it is suggested that spatial correlation through visual comparison be used in order to provide a better and more meaningful understanding of drought configuration at regional scales. This is more so for events like drought which have a "regional" aspect.

It was found that there is no meaningful quantitative correlation between SPI and DSI or VHI in different Fars counties. However, it was found that there is a meaningful visual spatial correlation between VHI and SPI during 1998 - 2007 (as shown in Figure 5). For SWI, and its correlation with DSI and VHI, the local data of each county was analyzed using the Pearson correlation. The correlation results are meaningful due to the small areas covered by each county.

In this research, drought monitoring was performed on a regional scale rather than at local individual stations. Although the variations in vegetation indices can help us understand the effect of climatic factors on local vegetation cover, the variations are of little practical value when preparing large-scale mitigation plans. The more we understand the relationships between precipitation, groundwater levels, and vegetation indices (on a regional level), the more insight we will have into drought onset and severity. Average VHI and DSI values of all counties in the study area were calculated as "average VHI" and "average DSI" and their correlation with precipitation data and SWI were examined. The results of individual stations showed better correlations between VHI and/or DSI val- 


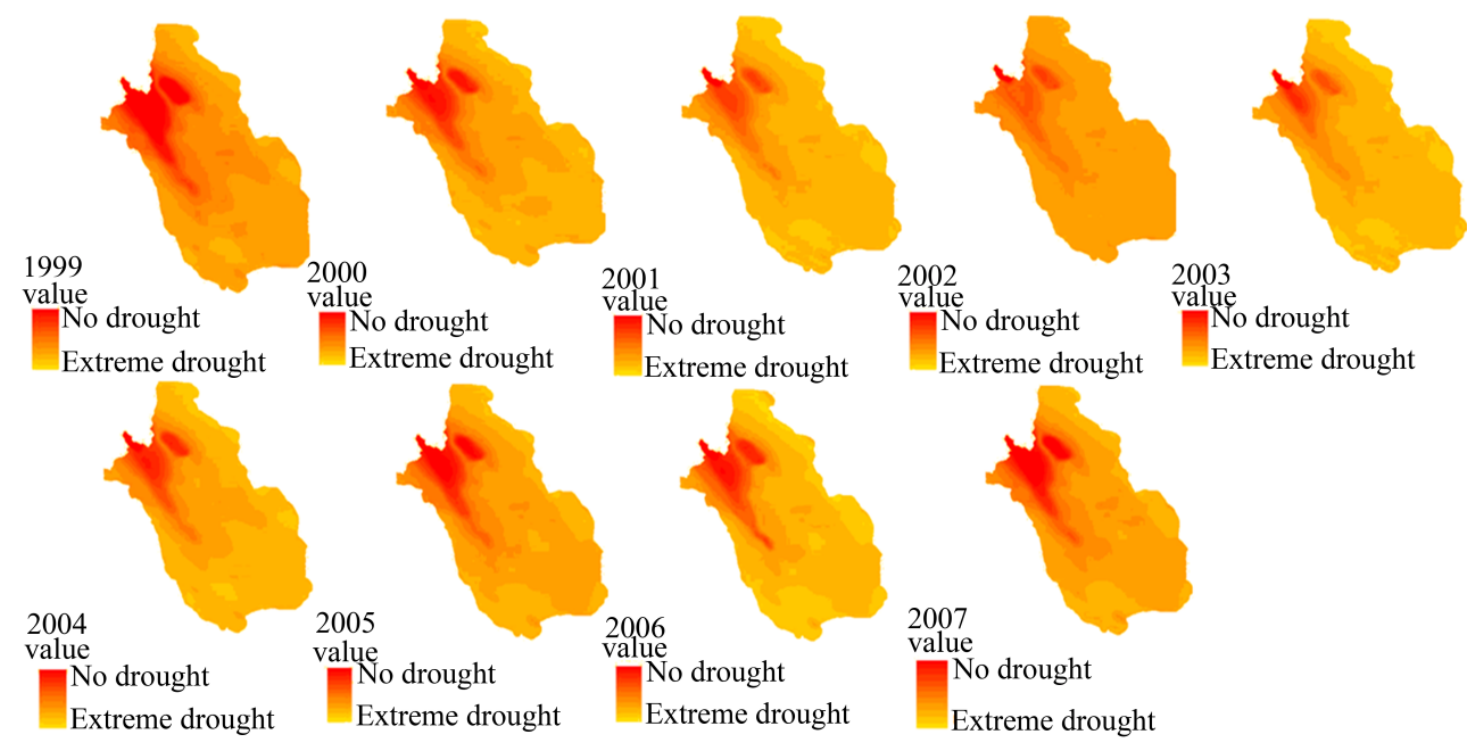

Figure 6. Drought severity classes map.

ues and same-month SWI. A correlation coefficient of 0.9 was obtained for VHI and SWI, indicating that the majority of vegetation lands cover is due to ground water irrigation.

The correlation coefficients of 14 counties show a strong correlation between VHI and SWI. However, in the period explored, there were various intensities of drought. The Ministry of Agriculture of Iran indicates good yield data for the same time period. The DSI maps, which were extracted from NDVI maps, also show reasonable vegetation cover during these ten years, which confirms rational yields. The Ground Water Department of Fars has recently warned of a significant decrease in aquifer levels for all agricultural plains. This type of water consumption in the most important agricultural part of Iran is unsustainable, and could result in a potentially severe food security crisis.

\section{Conclusions}

SPOT-Vegetation maps are reliable substitutes for any missing or cloudy NOAA-AVHRR data that was collected from 1998 to the present. The SPI maps reveal that meteorological drought and stress appear mostly in the southern, central, and eastern parts of the province of Fars; the years with severe drought during the study period appear to be from 2001 to 2003. Furthermore, VHI maps indicate a high visual correlation with SPI, but the quantitative correlations for each county do not provide reliable results. When the scales of the parameters are different, there is the possibility of weak correlations even when in reality one parameter is entirely dependent on the other. Therefore, instead of correlation coefficients, spa- tial correlation through visual comparison provides a better and more meaningful picture. This is especially true for events like drought which have a "regional" aspect. The DSI maps indicate good vegetation conditions for the majority of the study periods. Good vegetation cover conditions cannot be confirmed by looking at the "Precipitation-DSI" Pearson correlation or the "Precipitation-NDVI" results. In arid and semi-arid climate regions which use ground water for irrigation because of a lack of precipitation, vegetation cover is not only related to precipitation. A strong Pearson correlation between DSI and the same month SWI for the majority of Fars counties can be attributed in part to the irregular water consumption of the region's farmers. The main cause of this kind of irregular water consumption is the "assurance purchase law" for agricultural products from the government. If a region shows positive vegetation indices (as demonstrated through satellite-based images) despite being located in an arid or semi-arid region, it is very possible that the actual precipitation and ground water resource conditions are being misrepresented. Based on the finding of this research, it is recommended that the Iranian government develop and use hydrological and meteorological drought-risk maps not only for the province of Fars, but for the entire country.

\section{References}

[1] M. Hulme and P. Kelly, "Exploring the Links between Desertification and Climate Change," Environment, Vol. 35, No. 6, 1993, pp. 4-11. doi:10.1080/00139157.1993.9929106

[2] Intergovernmental Panel on Climate Change, "Climate 
Change 2001: Impacts, Adaptation, and Vulnerability,” Cambridge University Press, Cambridge, 2001.

[3] F. Kogan, "Global Drought Watch from Space,” Bulletin of the American Meteorological Society, Vol. 78, No. 4, 1997, pp. 621-636. doi:10.1175/1520-0477(1997)078<0621:GDWFS >2.0.C O;2

[4] F. Kogan, "Drought: A Global Assessment," Routledge, London, 2000.

[5] L. Eklundh, "AVHRR NDVI for Monitoring and Mapping of Vegetation and Drought in East African Environments," Meddelanden farn Lunds Universitets Geografikska Institutioner Lund University Press, Lund, 1996.

[6] A. Singh, L. McIntyre and L. Sherman, "Microarray Analysis of the Genome-Wide Response to Iron Deficiency and Iron Reconstitution in the Cyanobacterium Synechocystis sp. PCC 6803,” Plant Physiology, Vol. 132, No. 4, 2003, pp. 1825-1839. doi:10.1104/pp.103.024018

[7] C. Bhuiyan, R. Singh and F. Kogan, "Monitoring Drought Dynamics in the Aravalli Region (India) Using Different Indices Based on Ground and Remote Sensing Data,” International Journal of Applied Earth Observation and Geoinformation, Vol. 8, No. 4, 2006, pp. 289-302.

[8] B. E. Gadisso, "Drought Assessment for the Nile Basin Using Meteosat Second Generation Data with Special Emphasis on the Upper Blue Nile Region,” International Institute for Geo-information Science and Earth Observation, Enschede, 2007.

[9] P. R. Bajgiran, et al., "Using AVHRR-Based Vegetation Indices for Drought Monitoring in the Northwest of Iran," Journal of Arid Environments, Vol. 72, No. 6, 2008, pp. 1086-1096. doi:10.1016/j.jaridenv.2007.12.004

[10] F. N. Kogan, "Droughts of the Late 1980s in the United States As Derived from NOAA Polar Orbiting Satellite Data," Bulletin of the American Meteorological Society, Vol. 76, No. 5, 1995, pp. 655-668.

doi:10.1175/1520-0477(1995)076<0655:DOTLIT $>2.0 . C$ $\underline{\mathrm{O} ; 2}$

[11] F. N. Kogan, "Operational Space Technology for Global Vegetation Assessment," Bulletin of the American Meteorological Society, Vol. 82, No. 9, 2001, pp. 1949-1964. doi:10.1175/1520-0477(2001)082<1949:OST FGV $>2.3 . \mathrm{CO} ; 2$

[12] NOAA Satellite and Information Service, 2011. http://noaasis.noaa.gov/NOAASIS/ml/avhrr.html

[13] Spot-Vegetation Programme, 2011. http://www.vgt.vito.be/

[14] F. Achard, et al., "Collection and Pre-processing of NOAA AVHRR 1 km Resolution Data for Tropical Forest Resource Assessment,” TREES Series A: Technical Document No. 2, European Commission, Luxembourg, 1994, p. 56.

[15] E. Duchemin, "Hydroelectricity and Greenhouse Gases: Emission Evaluation and Identification of Biogeochemical Processes Responsible for Their Production,” PhD Thesis, Université du Québec à Montréal, Montréal, 2000.
[16] B. N. Holben, "Characteristics of Maximum-Value Composite Images from Temporal AVHRR Data," International Journal of Remote Sensing, Vol. 7, No. 11, 1986, pp. 1417-1434. doi:10.1080/01431168608948945

[17] V. Cuomo, et al., "Detection of Inter-Annual Variation of Vegetation in Middle and Southern Italy during 19851999 with 1 km NOAA AVHRR,” Journal of Geophysical Research, Vol. 106, No. D16, 2001, pp. 17863-17876. doi:10.1029/2001JD900166

[18] M. Lanfredi, R. Lasaponara, T. Simoniello and M. Macchiato, "Multiresolution Spatial Characterization of Land Degradation Phenomena in Southern Italy form 1985 to 1999 Using NOAA-AVHRR Data,” Geophysical Research Letters, Vol. 30, No. 2, 2003, pp. 1069-1081. doi:10.1029/2002GL015514

[19] L. Telesca and R. Lasaponara, "Pre- and Post-Fire Behavioral Trends Revealed in Satellite NDVI Time Series," Geophysical Research Letters, Vol. 33, 2006, Article ID L14401, pp. 1-4.

[20] NOAA Satellite and Information Service, 2011. http://noaasis.noaa.gov/NOAASIS/ml/calibration

[21] L. P. Di, D. C. Rundquist and L. H. Han, “Modeling Relationships between NDVI and Precipitation during Vegetative Growth Cycles," International Journal of Remote Sensing, Vol. 15, No. 10, 1994, pp. 2121-2136. doi:10.1080/01431169408954231

[22] G. L. John, D. Yuan, R. S. Lunetta and C. D. Elvidge, “A Change Detection Experiment Using Vegetation Indices," Photogrammetric Engineering and Remote Sensing, Vol. 64, No. 2, 1998, pp. 143-150.

[23] J. P. Malingreau and A. S. Belward, "Scale Consideration in Vegetation Monitoring Using AVHRR Data," International Journal of Remote Sensing, Vol. 13, No. 12, 1992, pp. 2289-2307. doi:10.1080/01431169208904269

[24] S. E. Marsh, J. L. Walsh, C. T. Lee, L. R. Beck and C. F. Hutchinson, "Comparison of Multi-Temporal NOAA-AVHRR and SPOT-XS Satellite Data for Mapping Land Cover Dynamics in the West African Sahel,” International Journal of Remote Sensing, Vol. 13, No. 16, 1992, pp. 2997-3016. doi:10.1080/01431169208904098

[25] B. C. Reed, et al., "Measuring Phenological Variability from Satellite Imagery,” Journal of Vegetation Sciences, Vol. 5, No. 5, 1994, pp. 703-714. doi:10.2307/3235884

[26] J. Campbell, “Introduction to Remote Sensing," The Guilford Press, New York, 1987.

[27] T. M. Lillesand and R. W. Kiefer, "Remote Sensing and Image Interpretation,” John Wiley \& Sons, New York, 1994.

[28] T. McKee, N. Doesken and J. Kleist, "The Relationship of Drought Frequency and Duration to Time Scales," Proceedings of the 8th Conference of Applied Climatology, Anaheim, 17-22 January 1993, pp. 179-184.

[29] C. Bhuiyan, "Various Drought Indices for Monitoring Drought Condition in Aravalli Terrain of India," Proceedings of the XXth ISPRS Conference, Istanbul, 12-23 July 2004, pp. 907-912. 